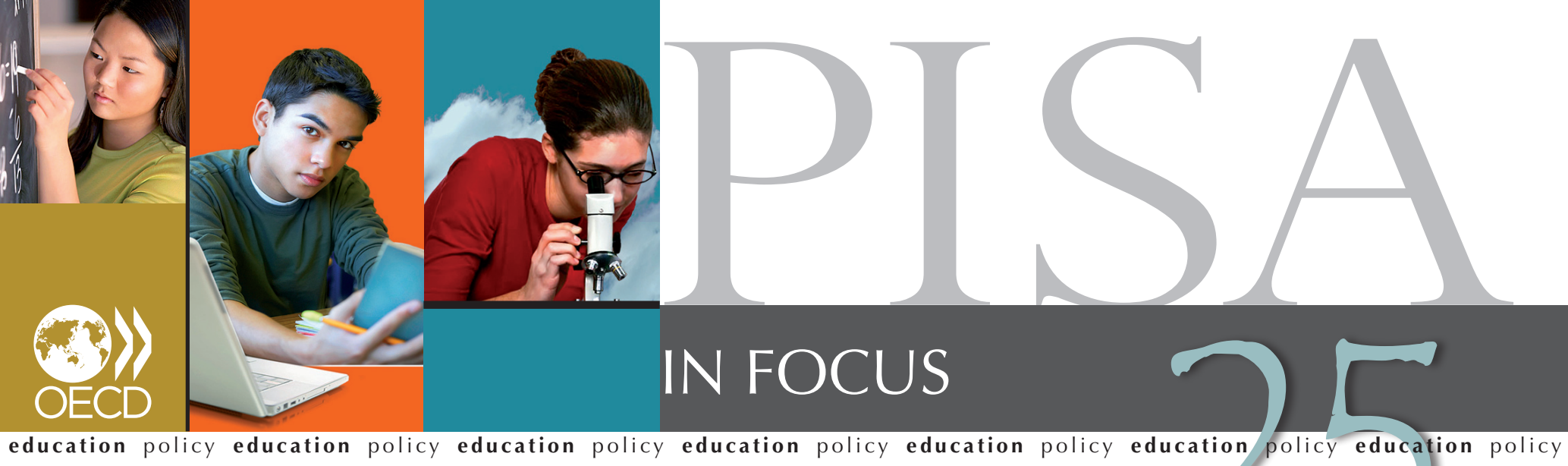

\title{
Are countries moving towards more equitable education systems?
}

- PISA results show that no country or economy has reached the goal of creating a completely equitable education system, but some are much closer than others.

- Some countries and economies have shown that improvements in equity can be achieved at the same time as improvements in overall performance, and in a relatively short time.

PISA has consistently shown a link between disadvantage and poor performance in school...
Ideally, school systems provide high-quality educational opportunities for all students, irrespective of the students' backgrounds. Students from socio-economically advantaged families and those from disadvantaged families should be equally likely to succeed in school. That is the ideal, anyway. In most countries, the reality looks a lot different. PISA results have consistently shown that socio-economic disadvantage is linked to poor performance in school. In fact, on average across OECD countries, disadvantaged students are twice as likely to be among the poorest performers in reading compared to advantaged students. On average, a socio-economically advantaged student scores 88 points higher on the PISA reading test than a socio-economically disadvantaged student, a difference that is equivalent to more than two years of schooling.

Yet the fact that countries and economies vary in the degree to which learning outcomes are linked to socio-economic background demonstrates that social background is not destiny, and that policy and practice can make a difference. Moreover, countries can pursue equitable learning outcomes while also moving towards high student performance. In the PISA 2009 survey, many of the countries and economies with the greatest equity in student outcomes are also top performers. Students in Canada, Estonia, Finland, Hong Kong-China, Iceland, Korea, Liechtenstein and Norway score above the OECD average in reading, and the difference in performance between advantaged and disadvantaged students is less than 70 score points. Other countries and economies also achieve equitable learning outcomes, but their students do not perform as well. 
Azerbaijan, Indonesia, Jordan, Macao-China, Qatar, Serbia, Thailand and Tunisia are as equitable as the preceding group of countries, but their students score below the OECD average in reading. The difference in reading performance between advantaged and disadvantaged students is highest - more than 100 score points - in Argentina, Austria, Belgium, Bulgaria, Dubai (UAE), France, Germany, Hungary, Israel, Luxembourg, New Zealand, Panama, Peru, the United States and Uruguay.

\section{... but that doesn't mean that the link is unbreakable.}

The fact that school systems vary in the degree to which they allow socio-economic differences to become differences in performance is an indication that any obstacles posed by disadvantaged social background can be overcome. While some of those differences may be attributable to culture, the fact that the relationship has changed significantly in some countries suggests that policy and practice can make a difference.

\section{Country/economy's equity and performance in PISA 2009}

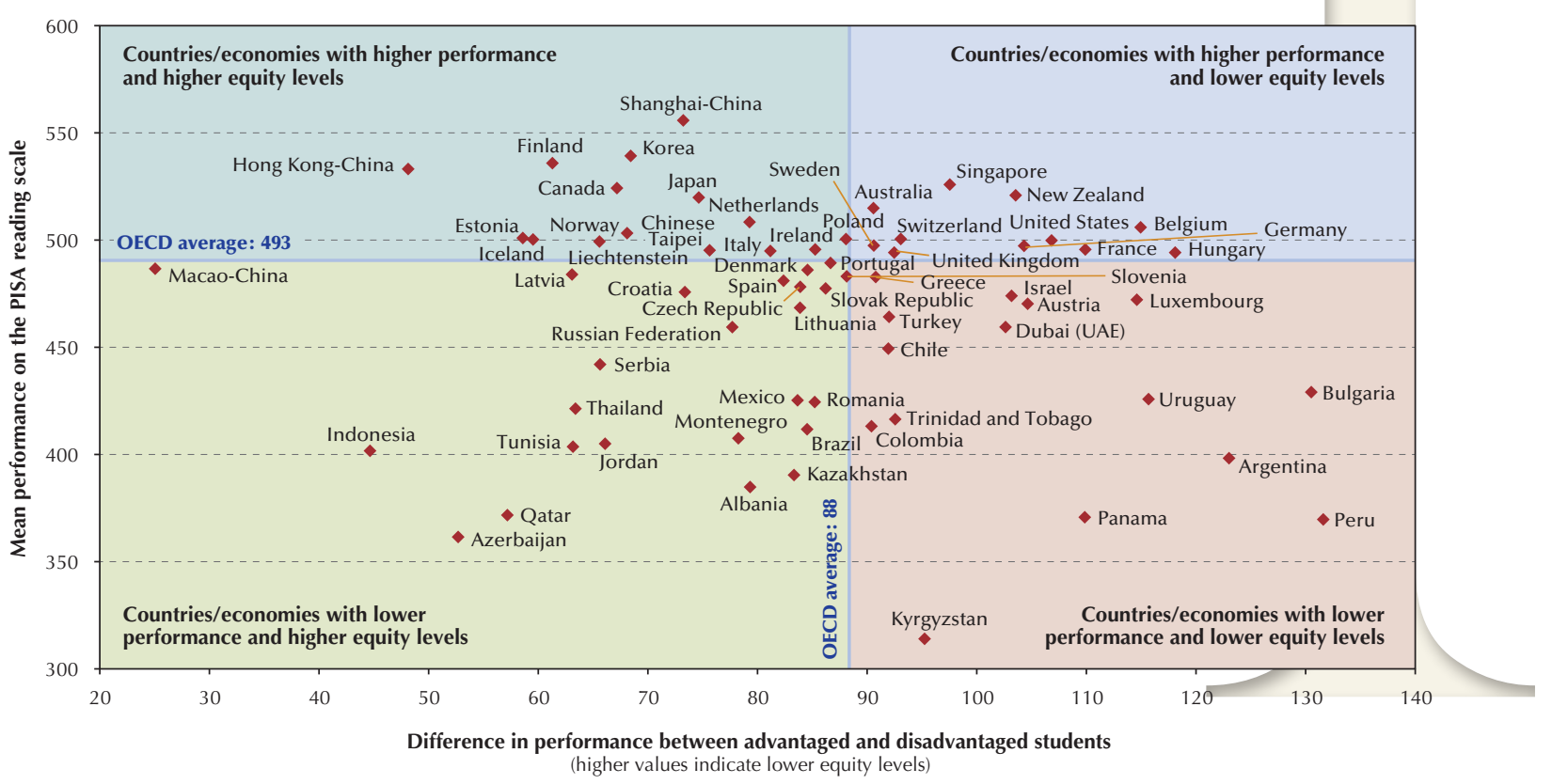

Sources: OECD (2010), PISA 2009 Results: What Students Know and Can Do, Volume I, OECD Publishing, Table I.2.3; and OECD (2010), PISA 2009 Results: Overcoming Social Background, Volume II, OECD Publishing, Table II.3.1.

Many countries and economies have made notable progress in narrowing the performance gaps between advantaged and disadvantaged students while simultaneously improving overall performance. This shows that education systems can reduce the extent to which differences in socio-economic background relate to student performance while promoting learning for all students. Comparing results from PISA 2000 and PISA 2009 reveals that, in Albania, Chile, Germany and Latvia the relationship between students' socio-economic status and their reading performance weakened and students' overall reading performance improved. In Germany, for example, the performance gap between advantaged and disadvantaged students narrowed by more than 25 score points and the average reading performance improved by 13 points. In Chile, average performance in reading improved by 40 score points and the performance gap between advantaged and disadvantaged students narrowed by more than 15 score points. 


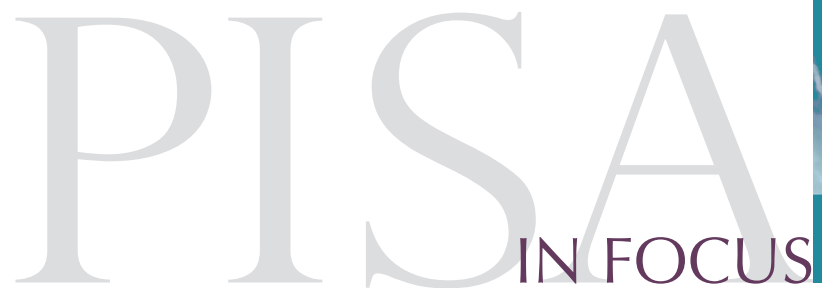

Other countries and economies, namely Canada, the Czech Republic, Hong Kong-China, Mexico and the United States, also improved their equity levels without a concurrent improvement in overall performance.

The right policies can help to weaken the link.

In Albania, Chile, Germany and Latvia, the association between socio-economic status and reading performance weakened between 2000 and 2009 while overall performance improved. Equity and performance improved simultaneously in these countries either because students from all backgrounds improved, with largest improvements seen among disadvantaged students (e.g. in Albania and Chile) or because although the performance of advantaged students did not change significantly, that of disadvantaged students did (for example, in Germany and Latvia).
Education policies that can foster improvements in equity and performance can include giving more and better support to disadvantaged students, who start school with deficits in their education; ensuring that all schools provide high-quality instruction; and offering additional educational opportunities to disadvantaged students, as their parents might not be able provide them. More support could be given to schools with large disadvantaged student populations or to disadvantaged students within schools. Broader social policies that help to ensure that the life experiences of advantaged and disadvantaged students are not that different, either at home - crucially, before students enter formal education - or in school can also promote both equity and high performance.

Change in equity and performance levels between 2000 and 2009

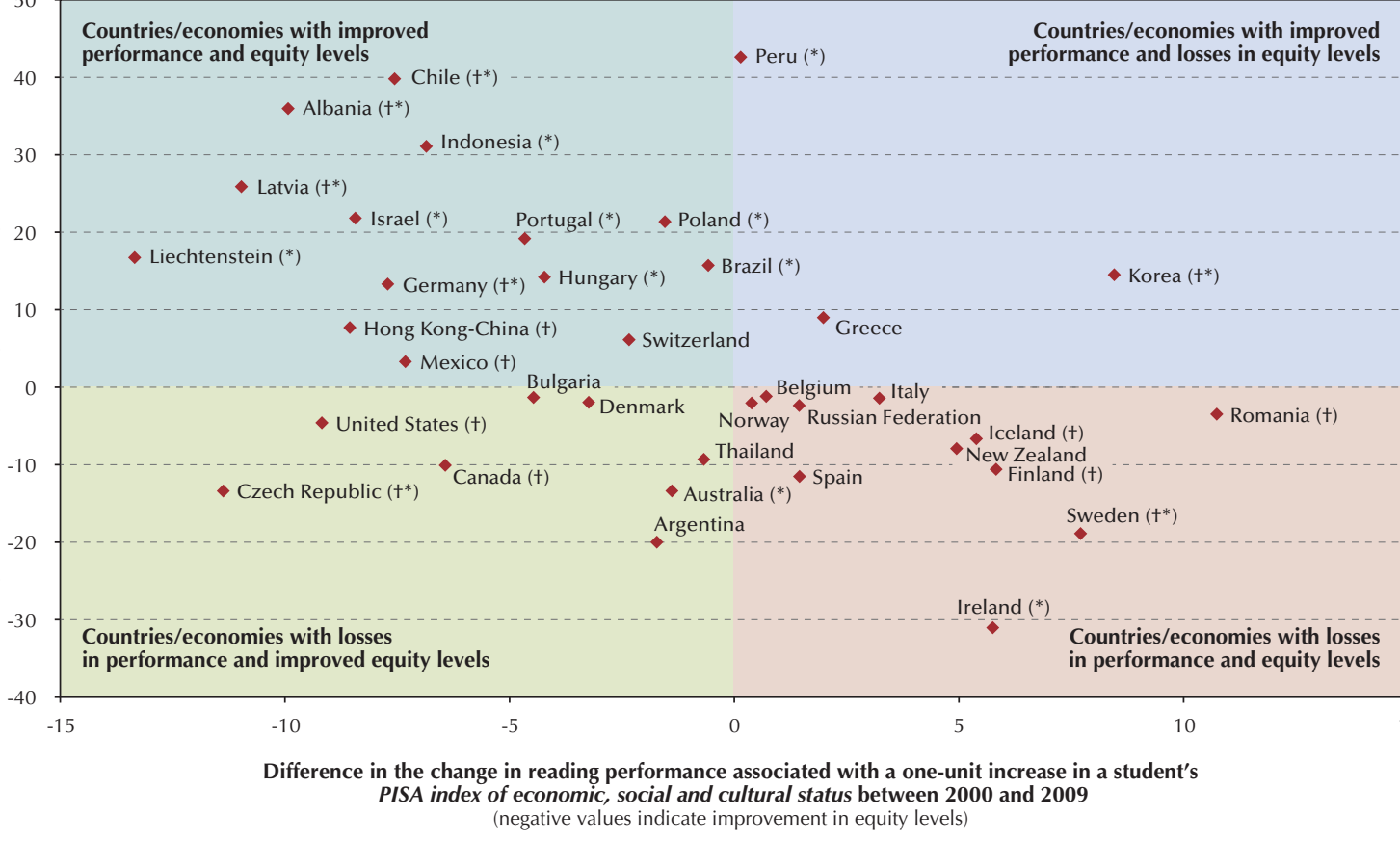

Difference in the change in reading performance associated with a one-unit increase in a student's PISA index of economic, social and cultural status between 2000 and 2009 (negative values indicate improvement in equity levels)

Note: The change in reading performance associated with a one-unit increase in a student's PISA index of economic, social and cultural status is usually referred to as the the slope of the socio-economic gradient and is the slope of a regression of socio-economic status on student reading performance. The difference in this change between 2009 and 2000 is presented in the horizontal axis.

† Change in equity is statistically significant ${ }^{*}$ Change in performance is statistically significant

Source: OECD (2010), PISA 2009 Results: Learning Trends, Volume V, OECD Publishing, Tables V.2.1 and V.4.3. 
All these policies that promote equity and overall performance in a school system are based on the premise that students should compete on a level playing field, and that if socio-economic disadvantage deprives students of having the same opportunities other students enjoy, these opportunities need to be provided by the school system.

Socio-economic status in PISA is measured through the PISA index of economic, social and cultural status (ESCS). This index combines students' responses on their parents' occupations and educational attainment, and their reports on the cultural possessions and educational resources available in the students' home. Advantaged students are those in the top quarter of the ESCS distribution within their country; disadvantaged students are those in the bottom quarter. Poor-perfoming students are those in the bottom quarter of a country's performance distribution.
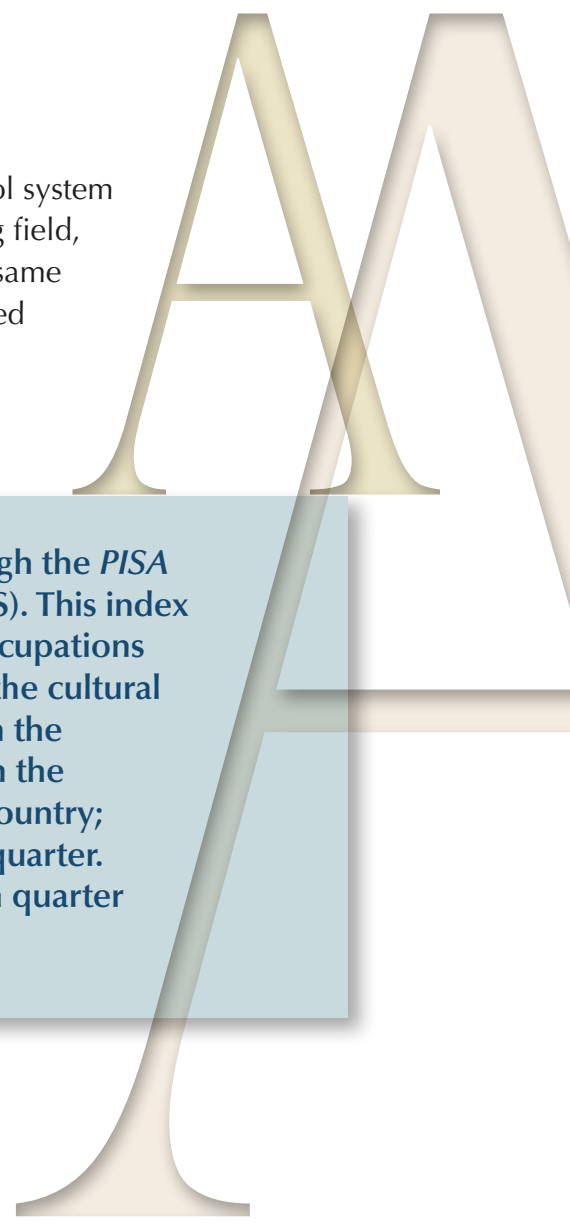

The bottom line: Although no country or economy has achieved the goal of developing a completely equitable education system, with the right policies, some have been able to weaken the link between socio-economic background and performance. This proves that it should not be considered inevitable that students from disadvantaged backgrounds perform poorly in school. All students should have the same opportunities to succeed in school, regardless of their backgrounds.

\section{For more information}

Contact Guillermo Montt (Guillermo.MONTT@oecd.org)

See OECD (2010), PISA 2009 Results: Overcoming Social Background: Equity in Learning Opportunities and Outcomes, Volume II, PISA, OECD Publishing,

OECD (2010), PISA 2009 Results: Learning Trends: Changes in Student Performance Since 2000, Volume V, PISA, OECD Publishing, Supporting data.

\section{Visit}

www.pisa.oecd.org

www.oecd.org/pisa/infocus 